\title{
Strategy for developing a future support system for the Vasa warship and evaluating its mechanical properties
}

\author{
Thomas Lechner $^{1^{*}}$, Ingela Bjurhager ${ }^{2}$ and Robert I Kliger $^{1}$
}

\begin{abstract}
To maintain the integrity of the Vasa warship after salvage in 1961, conservation treatment with polyethylene glycol was carried out to prevent the collapse of cell walls. This treatment had negative effects on the strength and stiffness of the oak and the hull structure has been found to slowly deform over time. It is of interest to construct a three-dimensional numerical computer model to model and predict the deformation of the warship. This creates difficulties related to the complexity of measuring the detailed material properties that are required as input. In this context, a non-destructive methodology to predict the stiffness of the Vasa oak in terms of moduli of elasticity in the three principal directions of timber at critical positions in the ship would be useful. The twofold aim of the paper is to propose a strategy for a support system and to conduct an on-site assessment of the warship to predict the mechanical properties of the Vasa oak material. This paper also contains an up-to-date review of all essential mechanical data measured on the Vasa oak. The preliminary investigation using an X-ray technique to investigate the density properties produced promising results for future use in the evaluation of the mechanical performance. Based on these results, a procedure to establish the stiffness properties of the Vasa oak in terms of MOE was suggested, using a combination of data from previous measurements, in combination with extended tests on Vasa oak specimens and an X-ray-based density calibration procedure. The general complexity of the Vasa warship can be mainly attributed to large variations in the properties of Vasa oak due to surface degradation, chemical treatment and the disintegration of the cell-wall structure originating from centuries of waterlogged conditions. That causes difficulties when assessing mechanical and physical properties on a structural level. A combination of visual inspection together with $\mathrm{X}$-ray investigation is of great importance to evaluate those properties and to obtain more accurate estimates. The results from evaluating mechanical properties can serve as input in a numerical model and serve as a foundation for decision-making relating to the modification of the support system.
\end{abstract}

Keywords: On-site assessment, Vasa warship, Timber structures, Non-destructive testing (NDT), Vasa oak, Mechanical properties, Polyethylene glycol (PEG)

\section{Background}

The Vasa warship is one of the most important national treasures of Sweden. After the launch in Stockholm Harbour, the "jewel" of the Swedish Navy experienced difficulty in terms of stability and manoeuvrability and sank on her maiden voyage in 1628. In 1956, the warship was located on the seabed and was salvaged in 1961. It was also at this point that the resurrection of the hull

\footnotetext{
* Correspondence: thomas.lechner@chalmers.se

'Department of Civil and Environmental Engineering, Chalmers University of Technology, SE-412 96 Gothenburg, Sweden

Full list of author information is available at the end of the article
}

began. Since 1990, the ship has been on display to the public at the Vasa Museum.

The shipworm-hostile seabed conditions and the anaerobic environment at the discovery site preserved the condition of the warship for several centuries, even though a certain degree of physical and chemical modification and degradation occurred [1-3].

In order to maintain the integrity of the Vasa, conservation treatment with polyethylene glycol (PEG) was carried out for a period of 17 years after the salvage $[4,5]$. This treatment prevented the hull from serious shrinkage and distortion that would otherwise have caused the 
collapse of the cell walls when the hull dried. However, PEG is known to have a negative impact on wood, in terms of reduced strength and stiffness [6-8].

Structural investigations of the warship were not initiated until the beginning of the 21st century, when data on on-going deformation were collected. At about the same time, an investigation of different reinforcement concepts for the ship and/or its support cradle was undertaken and different simple finite element (FE) models were also constructed for single cross-sections of the hull to predict future deformation and structural behaviour for different support scenarios $[9,10]$. No final decisions have as yet been made about how to support the hull and prevent further movement and deformation. However, research has focused increasingly on the mechanical properties of Vasa oak and the way they are influenced by chemical degradation and PEG content. In the first stage, the compression strength in the radial direction and tensile strength and stiffness in the longitudinal direction of both Vasa oak and PEGimpregnated recent European oak (Quercus robur) have been investigated $[7,8]$. In 2013, a new support structure project was initiated with the aim of modelling the structural behaviour of the entire ship. For this reason, a holistic approach is recommended and parameters such as geometry, joints, load transfer within the warship and load transfer from the warship to the existing support cradle have to be thoroughly explored. Material parameters such as stiffness in terms of moduli of elasticity (MOE) and cross-sectional stiffness and strength need to be investigated in more detail than before, which is a difficult task in itself. Due to both natural variation in the Vasa oak and chemical degradation and softening due to PEG in the Vasa timbers, the stiffness and strength properties are expected to vary considerably at different positions. It is therefore desirable to develop a methodology which enables the quick and easy measurement of geometry, damage and predictions of strength and stiffness. Due to the unique nature of the material, the measurements should preferably be as non-invasive and non-destructive as possible.

\section{Aim of this paper}

The paper emphasises the problem areas of the Vasa warship primarily from a structural viewpoint, which is important for future decision-making relating to a new support system. The paper also contains an extensive literature review of all the essential mechanical data measured on Vasa oak to date. The overall twofold aim of this paper is to develop an on-site assessment strategy to predict the mechanical properties of the Vasa oak material at structural level and to propose a strategy for developing a new support system that distributes the loads from the hull structure to the cradle. In a support system of this kind, the distribution of the acting loads should be easy to monitor and the movement and deformation should be prevented.

\section{The Vasa warship - challenges of a general nature Deformation of the hull}

Challenges related to the Vasa that have previously been identified are of a both structural and material character. One general problem is the progressive deformation that has occurred since the ship was salvaged. The monitoring of the deformation behaviour only began in the late 1990s [11], when the movements of the warship started to be registered in more detail. At that time, problems with indentations on the hull from the support cradle attracted special interest [11]. The present cradle on the concrete slab, which is absolutely necessary for the support of the warship, consists of stanchions which transfer the loads from the ship to the slab via wooden wedges. Over the years, the number of stanchions has been more than doubled in order to reduce the local pressure on the hull, as has the number of wedges. This has proved successful to some degree, but the problem of heterogeneously distributed loads still remains. This is indicated by the wedges, which tend to work loose or be wedged harder as the ship moves and deforms.

The structure of the warship itself consists of 25 main frames providing stiffness to the side and bottom structures. It has been found that the deck beams in the frames have also undergone significant deformation [10]. Some of the wooden centreline columns supporting the beams have therefore been replaced with aluminium columns with greater stiffness.

However, despite all the efforts that have been made, the problems associated with local and global deformation still remain and the warship is slowly deforming at a more or less constant speed. Manual measurements performed between 1987 and 1999 registered deformation as large as 50 millimetres at the bow [10]. Measurements made later showed that the deformation increased by as much as $0.5 \mathrm{~mm}$ per year, see Figure 1 [9]. The most likely contributory factors to the relatively high deformation rate are the low stiffness in the wood and the connections, in combination with large forces applied to the hull. A certain small seasonal shrinkage/ swelling of the wood also needs to be considered. The deformation is of both a translational and a rotational character [11]. The latter at least is believed to be caused by asymmetrically distributed weight, e.g. the heavy bow mast, which, due to its inclination, is likely to induce lengthwise torsion in the warship.

\section{Modelling to improve the support of the ship}

In the late 1990s, different concepts for strengthening the warship's structure were investigated. It has already 


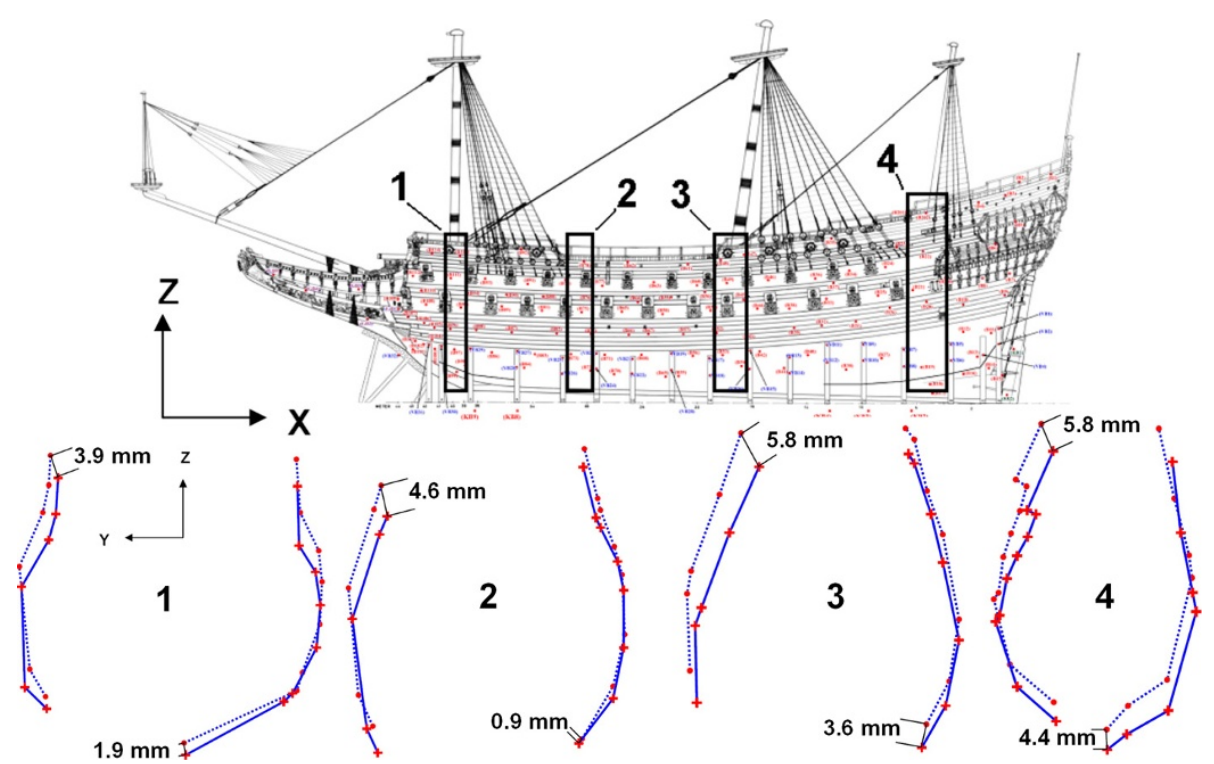

Figure 1 This figure shows the deformation pattern of the Vasa warship between 2000 and 2003, on both the starboard and the port side in four different sections. Figure adapted from [9].

been stated that the load transfer to the support structure is insufficient, leading to local indentations [7]. Different simplified finite element (FE) models of sections of the ship have since been established for cross-sections of the hull to predict the deformation $[9,10]$. In line with the actual measurements on the ship, the first sectional FE model (based on recent European oak MOE properties) showed that the main deflection and deformation is a translation of the side structure, deflection of the deck beams [10] and also deformation of the bilge, see Figure 2. The model and the material parameters were subsequently updated by Ljungdahl [9]. The updated model suggested that improved support, especially the strengthening of the main frames supporting the gun decks, would increase the stiffness of the ship's structure and probably reduce the speed of the time-dependent deformation. This FE model used material parameters from only a few Vasa oak samples as input. So, in order

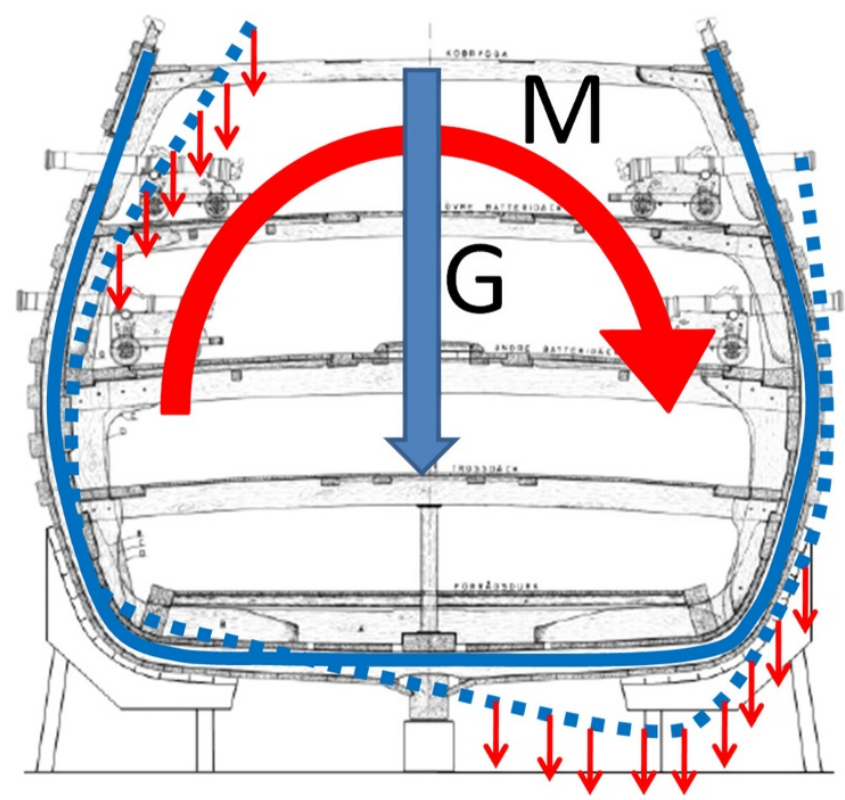

Figure 2 Cross-section of the Vasa warship. The deformation and translation are expected to be caused by deck structures that are not sufficiently stiff, weak connections between decks and the hull and asymmetrically distributed weight, e.g. the warship's inclined mast. 
to create an even more accurate model for the more precise prediction of the deformation over time, we believe that the material characteristics should be investigated globally on site using non-destructive testing, i.e. in a large number of positions, on the warship. In order to achieve this, essential material parameters, such as radial, tangential and longitudinal stiffness in terms of MOE, can be estimated on the basis of Vasa oak density. Generally, the mechanical performance of timber is strongly related to density $[12,13]$. By measuring density using non-invasive techniques, it is possible to predict the mechanical properties of wood without destroying precious material [14]. In the case of the Vasa, however, this is complicated by the impregnation agent, PEG. PEG is known to increase the density, while at the same time also reducing the mechanical properties. In particular, stiffness and strength properties in bending $[6,15]$ and radial/tangential compression [1] are affected. For Vasa oak, the PEG treatment has resulted in an increase in density of $20 \%$ or more $[16,17]$. The true density (i.e. without PEG) is otherwise expected to be lower than that of recent European oak and values of as low as $460 \mathrm{~kg} / \mathrm{m}^{3}$ for Vasa oak have been reported [15].

In the case of the Vasa, non-destructive testing (NDT) methods measuring the density must therefore be combined with additional chemical and quasi-non-destructive test methods in order to establish a density-properties relationship for PEG-impregnated archaeological oak with low biological degradation, i.e. Vasa wood (see the following sections for a detailed description of the material evaluation strategy). Once such a relationship is established, the mechanical performance at different locations in the ship could ideally be evaluated using NDT methods alone.
When the mechanical properties of the Vasa oak at several different locations are estimated, the information can be used in a much improved and detailed threedimensional FE model of the warship. A model of this kind can be used, among other things, to evaluate different options for improving the support of the ship (Figure 3), identifying critical zones in the warship subjected to high forces and/or large deformation, estimating load transfer from the hull to the present support structure and predicting the structural behaviour over time.

\section{The future of the Vasa warship - an outlook}

The assessment of the Vasa warship structure from a mechanical performance perspective requires a large number of measurements due to the large variation in the biologically/chemically degraded and PEG-impregnated oak. Any on-site assessment must include the continuous monitoring of deformation in the ship.

A complete three-dimensional model of the warship would be of great help when it comes to creating a new support system using advanced technology in order to protect the national treasure, the Vasa, for the future and prevent the ship's structure deforming still further. The proposed overall methodology is illustrated in Figure 4 and consists of four steps in a "living process" with the aim of maintaining the ship in its present shape, i.e. minimising (time-dependent) deformation. These steps are:

(1) On-site assessment of mechanical properties of the wood and description of the connections between elements

(2) Analysis of bearing capacity by computer modelling of the ship

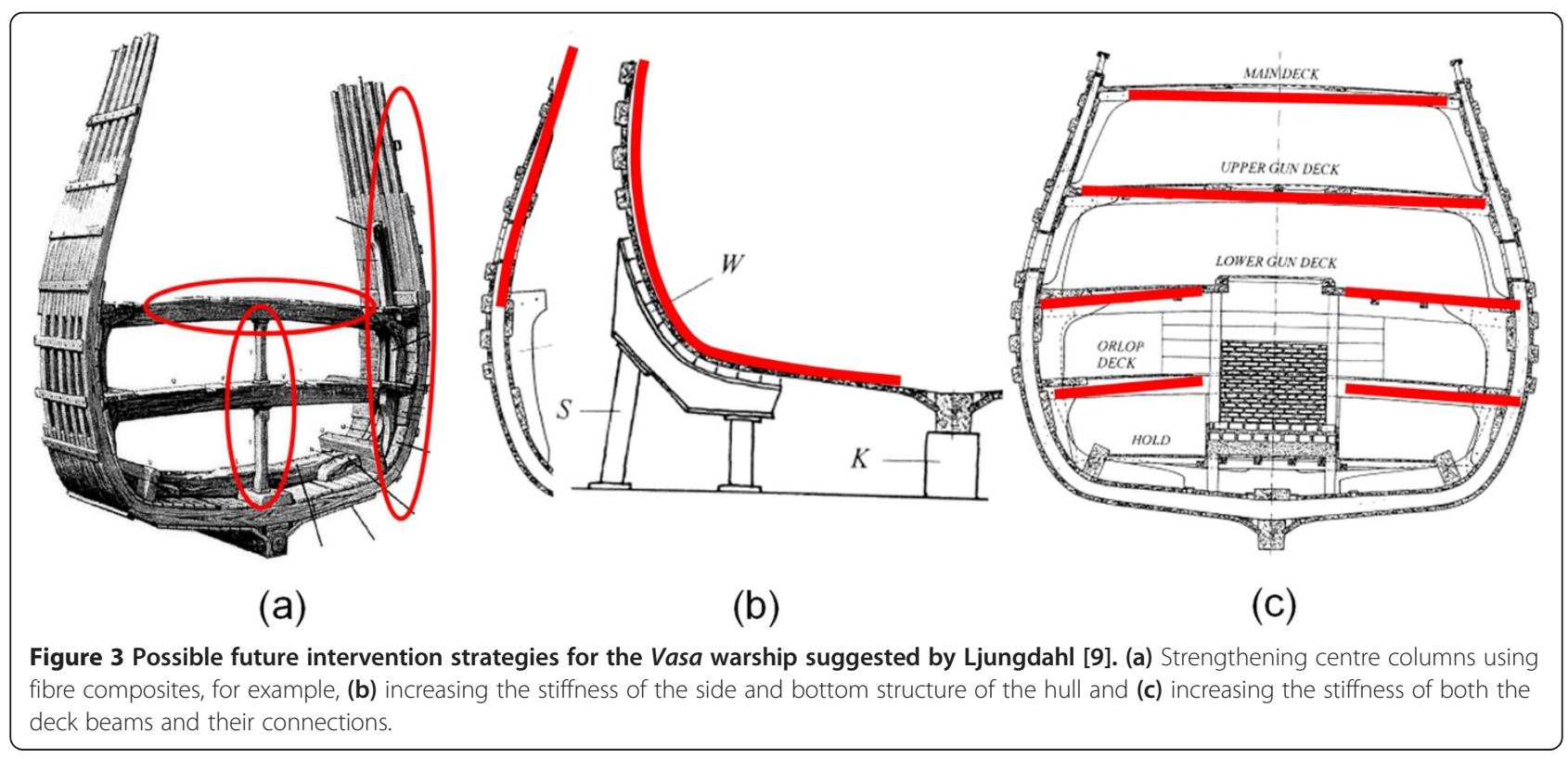




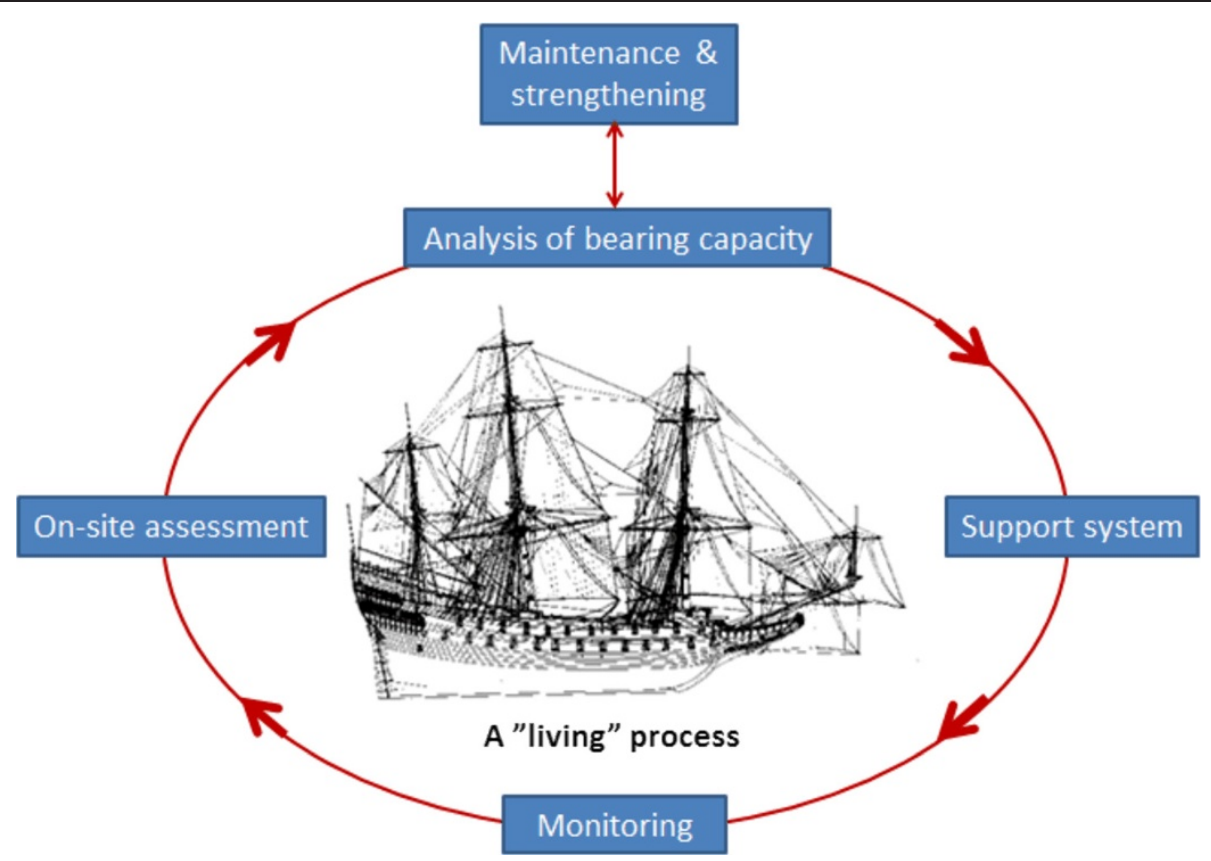

Figure 4 Proposed methodology for investigating the structural behaviour and preserving the Vasa warship.

(3) Choice of a new and improved support system based on the two previous steps and verification of the computer model

(4) Monitoring the ship after installing the system

The on-site assessment of the Vasa warship from a mechanical performance perspective (Step 1) involves a large number of measurements in different positions. This is expected to produce useful input data for a detailed FE model. The on-site assessment also includes monitoring deformation in the ship, which has already been initiated. This information could be used to compare predicted and measured deformation.

In addition to the determination of density, the X-ray technique is well established as a powerful tool for investigating the internal condition of the structure [14], especially the examination of connections and the integrity and condition of the structural components, such as those in the Vasa warship, see Figure 5. The investigation of connections in the Vasa warship is decisive for the load transfer within the hull and the load transfer from the hull to the existing support cradle and needs to be made in detail. This will also make it possible to measure and make visible geometry and joint configurations, as well as contact between hidden elements. Information of this kind is crucial for the accuracy of the FE model and supports the decision-making when it comes to ways of transferring the forces between the elements in the model.
Both the on-site assessment and the analysis of the bearing capacity (Steps 1 and 2) provide the basis for the choice of support (Step 3), where a decision will be made about how to support the ship in the best possible way. This implies a new and improved support system, preferably including load cells at each supporting position. An analysis of this kind could be very useful for decisions relating to strengthening and/or stiffening actions of the ship's structure and the second step may lead to the need to strengthen some parts of the hull, $\mathrm{cf}$. Figure 3.

Once the load cells are in place, the computer model can be verified and improved against both the reaction forces and the measured deformation. The whole system can then be part of the continued monitoring (Step 4) system, where the load levels are continuously controlled. If the loads exceed acceptable limits at some point, certain parts of the support structure might require adjustment. For this reason, a new support system would preferably be an (hydraulic) adjustable one. The degradation and thereby the reduction in the mechanical performance of the wood is expected to proceed over time. The overall process is therefore a cyclical one in which Steps 1-4 are repeated and the support of the ship is continuously adjusted and optimised according to the needs of the ship.

\section{On-site assessment of the Vasa warship}

In this section, we propose a detailed methodology for the on-site assessment (Step 1, cf. Figure 4) in the 


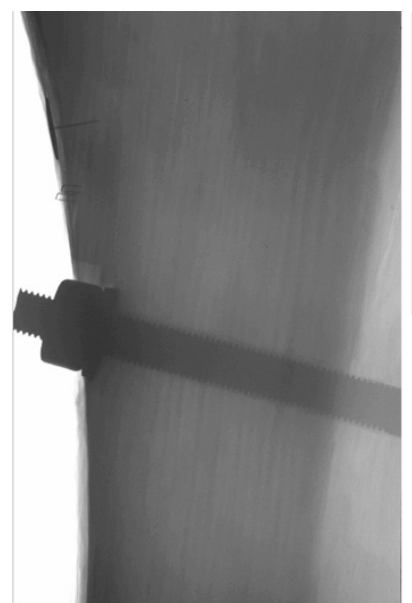

(a)

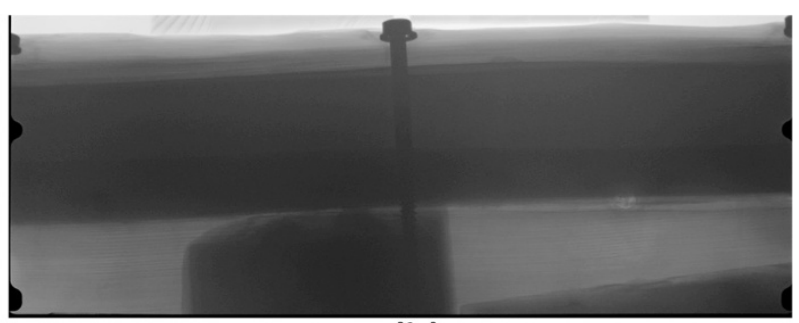

(b)

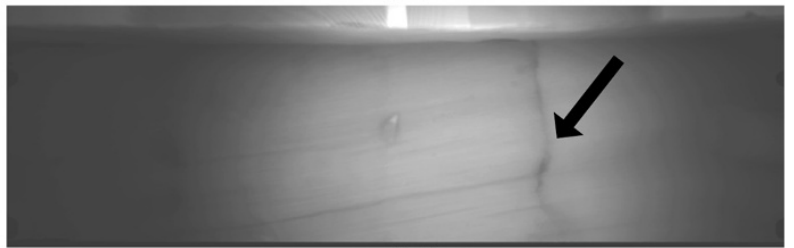

(c)

Figure 5 X-ray examination to evaluate the structural integrity of connections ( $a, b)$, components (b) and the internal condition (c). (a) Bolt connection of knee to the hull structure on upper gun deck (beam 5). (b) Integrity of structural components from upper gun deck, porthole 6. (c) Plank with internal fracture from stern, portside, 3rd gangway. The images were enhanced in Photoshop ${ }^{\varpi}$.

overall strategy, where the mechanical properties of the ship's structure are estimated using non-destructive and quasi-non-destructive test methods.

The on-site assessment of the timber properties of Vasa oak and of structural elements is essential for the continuous maintenance and preservation of historical timber structures. This is particularly important when the survival of an historical timber structure showing abnormal structural behaviour must be guaranteed. Abnormal behaviour can be expected when the strength and stiffness of a structure is reduced due to deterioration, conservation work, changes in climate and the natural ageing of old timber $[18,19]$ and also when the compatibility of material in connections and joints results in changes in the load-carrying capacity of the structure.

\section{Mechanical characteristics of archaeological wood and influence of PEG treatment}

Wood is an anisotropic material, i.e. the properties in different directions are different. These properties also depend on the species, the moisture content and natural growth defects. Moreover, in the case of the Vasa, degradation and chemical treatment (i.e. PEG impregnation) also have a powerful effect on the strength and stiffness properties $[6,15,16]$. The variation in mechanical performance at different positions in the enormous ship's structure is therefore expected to be larger than that in recent European oak. In General, waterlogged archaeological wood undergoes physical and chemical modifications as a result of erosion bacteria in anaerobic conditions, for example, causing the separation of the secondary cell-wall layers $[2,3,20]$. As the microstructure of the cell wall governs the strength characteristics in wood, cell-wall decomposition severely reduces the strength [6,7]. At the same time, the loss of wood substance results in lower density [21]. The dry density of a block of Vasa oak taken before the salvage and PEG impregnation was as low as $460 \mathrm{~kg} / \mathrm{m}^{3}$ [15]. This should be compared with recent (dry) oak with a density of approximately $700 \mathrm{~kg} / \mathrm{m}^{3}$ [22]. For this block of Vasa oak, a reduction in strength of at least $40 \%$ was also expected for the archaeological material in the study $[6,15]$. The stiffness properties of heartwood oak between the modulus of elasticity (MOE) in bending and compression showed a difference of more than 50\% compared with water-saturated recent European oak samples [15]. This difference lies in the range of $35 \%$ to $60 \%$ for the bending properties compared with water-saturated recent oak samples [15], but this does not necessarily mean that the stiffness is always reduced to the same degree in all cases [16]. Strength and stiffness loss in archaeological wood could be substantially larger, depending on the degree of decomposition [15].

However, the reduction in mechanical strength in Vasa oak due to biological degradation is probably not generally a major problem, as a large part of the Vasa consists of biologically resistant oak heartwood. This assumption is supported by studies of both the Vasa and other archaeological ships, such as the Bremen cog [15].

In contrast to biological degradation, PEG impregnation is instead expected to have a large impact on the mechanical performance of the Vasa. Impregnation with PEG is a well-known, successful method commonly used for conserving historical artefacts. PEG impregnation ideally results in a dimensional stabilising effect but unfortunately also in the softening of the wood and some 
degree of stiffness reduction. At the same time, bulking with PEG increases the density by $20 \%$ [17] or more.

\section{Mechanical properties of Vasa oak - a review}

An extensive review (summarised in Tables 1 and 2), including data from almost all the mechanical tests performed on wood from the Vasa warship, clearly shows that both the stiffness in terms of MOE and the strength of the wood are reduced (see Table 2). The data are mainly based on research from the past 10 years [23]. The size of the clear-wood specimens in the different studies ranges from $10 \mathrm{~mm}$ to $45 \mathrm{~mm}$, except for the tensile tests where the specimen length was $170 \mathrm{~mm}$.

The first mechanical tests on Vasa oak were carried out by Thunell in 1958 even before the warship was salvaged [24]. The test data are based on "one piece of oak" of unknown size. Thunell reported a 40\% loss in the bending and axial compression strength of waterlogged Vasa oak compared with recent (waterlogged) European oak, which is in agreement with data from other tests on archaeological wood [6]. At that time, no differences in mechanical performance were found between samples taken from the interior and the exterior part of the warship [24]. Chemical degradation with a subsequent reduction in strength has been confirmed later on [25]. However, as the majority of the chemical degradation is also believed to have taken place after the salvage [31], Thunell's results [24] are reasonable.

Mechanical tests on Vasa oak carried out much later by Ljungdahl [9] showed a reduction of the MOE in compression in the longitudinal direction (i.e. axial and parallel to the grain) of between $2 \%$ and $42 \%$. The corresponding figure for the MOE in compression in the tangential direction was $31 \%$. Strength properties in compression in both the longitudinal and tangential direction were reduced by $33 \%$ to $56 \%$ and $7 \%$ to $27 \%$ respectively. It is likely that the reduction in stiffness and strength is due to PEG. This is indicated by the density, which was $22 \%$ to $45 \%$ higher in Vasa oak than in recent European oak [8,9], indicating a high PEG content.

Investigations at a later date also produced similar results. Both the radial MOE in compression and strength in compression in the radial direction were decreased by approximately $50 \%$ in Vasa oak compared with recent European oak [32]. When it came to the MOE and strength in the tangential direction, the corresponding values were approximately $50 \%$ and $30 \%$ respectively. It was concluded that this was mainly due to micro-buckling and the more brittle plastic collapse of the ray cells in Vasa earlywood compared with recent European oak [29]. Furthermore, the radial MOE in compression and the radial compression strength were found to be negatively influenced by an increase in PEG content. The decrease could be described as approximately exponential $[1,26]$.

Bjurhager et al. [25] also carried out extensive tensile testing in the longitudinal direction on Vasa oak from four different locations in the warship. Compared with the reference specimens, the tensile strength of Vasa oak was reduced by an average of $40 \%$, but reductions of up to $80 \%$ were also observed [25]. From this summary, it can be concluded that the variation in mechanical properties is

Table 1 Density of Vasa oak [23]

\begin{tabular}{|c|c|c|c|c|c|c|}
\hline Source & Position & $\begin{array}{l}\text { Density } \\
{[\rho]}\end{array}$ & $\begin{array}{c}\text { Average } \\
{\left[\mathrm{kg} / \mathrm{m}^{3}\right]}\end{array}$ & $\begin{array}{c}\text { Standard deviation } \\
{\left[\mathrm{kg} / \mathrm{m}^{3}\right]}\end{array}$ & $\begin{array}{c}\text { No. of samples } \\
{[-]}\end{array}$ & Note \\
\hline Thunell [24] & & $\rho_{\text {basic }}$ & 460 & - & 10 & $\begin{array}{l}\text { Measured in watersat. } \\
\text { cond }(u=132 \%) \text {, no PEG }\end{array}$ \\
\hline Bjurhager et al. [25] & & $\rho_{\text {dry }}$ & 757 & 112 & 28 & $\mathrm{u}=0 \%, \mathrm{PEG}$ content $11.7(17.3) \%$ \\
\hline Ljungdahl [9] & & $\rho_{\text {cond }}$ & 1005 & - & - & $\mathrm{u}=7 \%, \mathrm{PEG}$ content unknown \\
\hline Ljungdahl [9] & & $\rho_{\text {cond }}$ & 848 & - & - & $\mathrm{u}=8 \%, \mathrm{PEG}$ content unknown \\
\hline Ljungdahl and Berglund [26] & & $\rho_{\text {cond }}$ & 1030 & 29 & 7 & $\mathrm{u}=9.7(0.9) \%$, PEG content 30.5 (3.0)\% \\
\hline Ljungdahl and Berglund [26] & & $\rho_{\text {cond }}$ & 1052 & 33 & 7 & $u=9.4(0.3) \%$, PEG content 25.7 (2.6)\% \\
\hline Bjurhager et al. [25] & & $\rho_{\text {cond }}$ & 784 & 132 & 28 & $u=7.8(0.5) \%$, PEG content $11.7(17.3) \%$ \\
\hline Ljungdahl and Berglund [26] & (centre) & $\rho_{\text {cond }}$ & 752 & 136 & 10 & $u=12.5(1.3) \%$, PEG content $2.8(3.4) \%$ \\
\hline Burman et al. [27] & (centre) & $\rho_{\text {cond }}$ & 748 & 141 & 5 & $\mathrm{u}=8.9(1.8) \%$, PEG content unknown \\
\hline Ljungdahl and Berglund [26] & (surface) & $\rho_{\text {cond }}$ & 854 & 146 & 10 & $u=11.8(0.6) \%$, PEG content 11.1 (12.1)\% \\
\hline Burman et al. [27] & (surface) & $\rho_{\text {cond }}$ & 749 & 117 & 5 & $\mathrm{u}=8.8(1.9) \%$, PEG content unknown \\
\hline Bjurhager et al. [25] & & $\rho_{\text {extracted,dry }}$ & 699 & 50 & 28 & $\mathrm{u}=0 \%$, after PEG extraction \\
\hline Bjurhager et al. [8] & & $\rho_{\text {extracted,cond }}$ & 592 & 105 & 1 & from SilviScan \\
\hline Bjurhager et al. [8] & & $\rho_{\text {extracted,cond }}$ & 701 & 170 & 1 & from SilviScan \\
\hline Bjurhager et al. [8] & & $\rho_{\text {extracted,cond }}$ & 806 & 628 & 1 & from SilviScan \\
\hline
\end{tabular}

$\mathrm{u}$ - moisture content; $(\ldots)$ - standard deviation; $\rho_{\text {dry }}$ - ovendry density; ; $\rho_{\text {cond }}$ - density in conditioned state $\left(23^{\circ} \mathrm{C}, \mathrm{RH} 53 \%\right) ; \rho_{\mathrm{extracted}, \mathrm{dry}}-$ density in extracted and ovendried state; $\rho_{\text {extracted,cond }}$ - density in extracted and conditioned state;Silviscan indicates density measured by Silviscan technique. 
Table 2 Mechanical properties of Vasa oak [23]

\begin{tabular}{|c|c|c|c|c|c|c|}
\hline 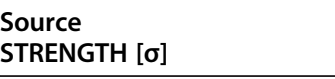 & Position & $\begin{array}{c}\text { Parameter } \\
{[\sigma]}\end{array}$ & $\begin{array}{c}\text { Average } \\
\text { [MPa] }\end{array}$ & $\begin{array}{c}\text { Standard deviation } \\
{[\mathrm{MPa}]}\end{array}$ & $\begin{array}{c}\text { No. of samples } \\
{[-]}\end{array}$ & Note \\
\hline \multicolumn{7}{|c|}{ Tensile strength in longitudinal (L) direction } \\
\hline Bjurhager et al. [28] & & $\sigma_{L, \text { tensile }}$ & 47.4 & 12.7 & 175 & $u=7.8(0.5) \%$, PEG content $11.7(17.3) \%$ \\
\hline Bjurhager et al. [8] & & $\sigma_{L, \text { tensile }}$ & 37.6 & 15.7 & 126 & \\
\hline Bjurhager et al. [8] & & $\sigma_{L, \text { tensile }}$ & 59.9 & 24.6 & 121 & \\
\hline Bjurhager et al. [8] & & $\sigma_{L, \text { tensile }}$ & 44.1 & 25.5 & 91 & \\
\hline \multicolumn{7}{|c|}{ Compression strength in longitudinal (L) direction } \\
\hline Thunell [24] & & $\sigma_{L, \text { compr. }}$ & 17.0 & - & 10 & $\begin{array}{l}\text { Measured in watersat. cond } \\
(u=132 \%) \text {, no PEG }\end{array}$ \\
\hline Ljungdahl [9] & & $\sigma_{L, \text { compr. }}$ & 39.7 & - & - & $u=7 \%$, PEG content unknown \\
\hline Ljungdahl [9] & & $\sigma_{L, \text { compr. }}$ & 26.2 & - & - & $\mathrm{u}=8 \%, \mathrm{PEG}$ content unknown \\
\hline \multicolumn{7}{|c|}{ Compression strength in radial $(\mathrm{R})$ direction } \\
\hline Ljungdahl and Berglund [29] & & $\sigma_{\mathrm{R}, \mathrm{compr}}$ & 8.5 & 1.0 & 7 & $u=9.7(0.9) \%$, PEG content 30.5 (3.0)\% \\
\hline Ljungdahl and Berglund [29] & (centre) & $\sigma_{R, \text { compr. }}$ & 12.9 & 3.7 & 10 & $u=12.5(1.3) \%$, PEG content $2.8(3.4) \%$ \\
\hline Burman et al. [30] & (centre) & $\sigma_{R, \text { compr. }}$ & 6.0 & 2.3 & 5 & $\mathrm{u}=8.9(1.8) \%$, PEG content unknown \\
\hline Ljungdahl and Berglund [29] & (surface) & $\sigma_{R, \text { compr. }}$ & 11.6 & 4.9 & 10 & $\mathrm{u}=11.8(0.6) \%$, PEG content $11.1(12.1) \%$ \\
\hline Burman et al. [30] & (surface) & $\sigma_{R, \text { compr. }}$ & 5.8 & 3.9 & 5 & $\mathrm{u}=8.8(1.9) \%$, PEG content unknown \\
\hline \multicolumn{7}{|c|}{ Compression strength in tangential $(\mathrm{T})$ direction } \\
\hline Ljungdahl [9] & & $\sigma_{\mathrm{T}, \mathrm{compr}}$ & 14.3 & - & - & $u=7 \%$, PEG content unknown \\
\hline Ljungdahl [9] & & $\sigma_{\mathrm{T}, \mathrm{compr}}$ & 11.1 & - & - & $\mathrm{u}=8 \%, \mathrm{PEG}$ content unknown \\
\hline Ljungdahl and Berglund [29] & & $\sigma_{\mathrm{T}, \mathrm{compr}}$ & 5.6 & 1.0 & 7 & $u=9.4(0.3) \%$, PEG content 25.7 (2.6)\% \\
\hline \multicolumn{7}{|c|}{ Modulus of rupture } \\
\hline Thunell [24] & & MOR & 34.0 & - & 10 & Measured in watersat. cond. ( $\mu$ 132\%) \\
\hline STIFFNESS [MOE] & & {$[E]$} & [GPa] & [GPa] & {$[-]$} & \\
\hline \multicolumn{7}{|c|}{ Compression and tensile MOE in radial $(\mathrm{R})$, tangential $(\mathrm{T})$ and longitudinal $(\mathrm{L})$ direction } \\
\hline Bjurhager et al. [28] & & $E_{L, \text { tensile }}$ & 7.40 & 1.30 & 175 & $\mathrm{u}=7.8(0.5) \%$, PEG content $11.7(17.3) \%$ \\
\hline Ljungdahl [9] & & $E_{L, c o m p r .}$ & 9.50 & - & - & $\mathrm{u}=7 \%$ (PEG content unknown) \\
\hline Ljungdahl [9] & & $\mathrm{E}_{\mathrm{L}, \mathrm{compr}}$ & 5.60 & - & - & $\mathrm{u}=8 \%$ (PEG content unknown) \\
\hline Ljungdahl and Berglund [29] & & $E_{R, c o m p r .}$ & 0.95 & 0.09 & 7 & $u=9.7(0.9) \%$, PEG content 30.5 (3.0)\% \\
\hline Ljungdahl and Berglund [29] & (centre) & $E_{R, c o m p r}$ & 1.29 & 0.40 & 10 & $u=12.5(1.3) \%$, PEG content $2.8(3.4) \%$ \\
\hline Burman et al. [30] & (centre) & $E_{R, c o m p r}$ & 0.80 & 0.40 & 5 & $\mathrm{u}=8.9(1.8) \%$, PEG content unknown \\
\hline Ljungdahl and Berglund [29] & (surface) & $E_{R, \text { compr. }}$ & 1.10 & 0.39 & 10 & $u=11.8(0.6) \%$, PEG content $11.1(12.1) \%$ \\
\hline Burman et al. [30] & (surface) & $E_{R, c o m p r}$ & 0.70 & 0.50 & 5 & $\mathrm{u}=8.8(1.9) \%$, PEG content unknown \\
\hline Ljungdahl [9] & & $\mathrm{E}_{\mathrm{T}, \mathrm{compr}}$ & 1.10 & - & - & $u=7 \%, P E G$ content unknown \\
\hline Ljungdahl [9] & & $\mathrm{E}_{\mathrm{T}, \mathrm{compr}}$ & 1.10 & - & - & $u=8 \%, P E G$ content unknown \\
\hline Ljungdahl and Berglund [29] & & $\mathrm{E}_{\mathrm{T}, \mathrm{compr}}$ & 0.72 & 0.16 & 7 & $\mathrm{u}=9.4 \%(0.3), \mathrm{PEG}$ content $25.7 \%(2.6)$ \\
\hline
\end{tabular}

u - moisture content; (...) - standard deviation.

large in the oak in the Vasa warship. This means that more detailed investigations of the properties at various locations in the ship's structure are necessary, in order to provide sufficient input for a computer model.

Various NDT methods for on-site evaluation of timber characteristics in the Vasa warship

Several investigation techniques are used for measuring both qualitative and quantitative parameters of timber structures [14,27,33]. For structures of significant cultural value such as the Vasa warship, one aim is to minimise the destruction of the object. Nondestructive testing (NDT) methods are therefore naturally preferable.

Most mechanical properties are highly related to the density of wood, e.g. MOE, the embedment strength in connections and the compression strength parallel and perpendicular to the grain $[12,13,34]$. Consequently, any 
evaluation of NDT techniques should preferably be directed towards an evaluation of density. These methods can include measurements with a Resistograph ${ }^{\odot}$ (measuring drilling resistance), X-ray, stress-wave and ultrasonic techniques, transmission time (Fakopp ${ }^{\oplus}$, Sylva-test ${ }^{\oplus}$ ) or hardness tests [35], for example. In the case of the Vasa warship, it was decided to determine the on-site density of the material with the density calibration procedure using X-ray equipment [36]. The method includes rendering images by scanning with $\mathrm{X}$ rays where the density is related to the greyscale in the images. In combination with density determination by $\mathrm{X}$-ray measurements, stress-wave techniques such as ultrasonic measurements are also of great interest. These measurements have demonstrated an ability to provide information on mechanical properties and could be applied to the load-bearing parts of the ship's structure for estimations of stiffness. Stress-wave techniques for the determination of the modulus are mainly governed by the speed of the wave propagation, which is, however, dependent on the density of the material, the internal condition of the timber and the moisture content [27].

\section{Relationship between density, MOE and PEG distribution}

Establishing a relationship between mechanical properties and density in the Vasa wood is, as mentioned previously, difficult due to the fact that the PEG treatment has increased the density but at the same time reduced the strength and stiffness properties by up to $50 \%$ [15]. It might, however, be possible to overcome this problem. The following approach to linking density data to the mechanical properties of PEG-impregnated Vasa oak is suggested.

(1) Mechanical testing of clear-wood specimens from Vasa oak in all three fibre directions (R, T, L) for the determination of the MOE, which is of primary interest as an input parameter in an FE model. Determination of specimen density using both Xray measurements and weight-volume measurements to validate the X-ray method as an accurate way of determining density. Determining the PEG content with commonly used extraction methods.

(2) Establishing relationships, first between density and PEG content and then between PEG content and the MOE to link the density and the MOE in the Vasa wood. At that point, data from both previous studies and the present study are used in order to increase the amount of data for statistical analysis.

(3) Non-destructive density measurements with the X-ray technique only on structural elements in the Vasa warship for the prediction and verification of the mechanical properties from the relationships established in Step 2.
In more detail, the following experiments are planned: in the first step, small clear wood samples measuring 26 $\times 26 \times 26\left[\mathrm{~mm}^{3}\right]$ of Vasa oak and reference specimens of recent European oak are weighed and X-rayed before the specimens are tested mechanically within the elastic region (i.e. tested at low load levels not causing residual deformation) before the extraction of PEG. The tests should be carried out in the three main directions of the timber $(\mathrm{R}, \mathrm{T}, \mathrm{L})$. From these tests, the MOE in all three directions $(\mathrm{R}, \mathrm{T}, \mathrm{L})$ can be determined and the density and PEG content can be measured using a minimum amount of material. The density of both Vasa oak and reference oak will be measured from volume-weight measurements and compared with X-ray measurements. The PEG content can be determined using methods such as Soxhlet extraction, nuclear magnetic resonance spectroscopy (NMR) or matrix-assisted laser desorption/ ionisation time-of-flight (MALDI-TOF) mass spectrometry $[3,25,37]$.

In the second step, the density is related (via the PEG content) to the MOE of the clear wood specimens from the Vasa warship with well-established PEG content for some samples but also from previous measured samples and statistically verified distribution [5].

The expected trend in the three principal directions of the Vasa wood is decreasing stiffness in terms of MOE with increasing density. These results can be used to illustrate the applicability and adaptability of the methods for the structural components and might serve as an input in FE modelling analysis.

In the third step, the mechanical properties will be predicted through non-destructive X-ray measurements of the average density of well-known components on site to evaluate and verify the applicability of the method. This could be achieved by the relationships established between PEG content, density and the MOE in Step 2. The PEG content, however, varies in depth $[8,20]$ and has a negative impact on the mechanical performance $[38,39]$. As it is impossible to monitor the depth of the PEG visually or by X-ray, a general PEG profile, based on previous measurements from different locations on the Vasa warship and at different depths, will serve as a further link to estimate the stiffness properties in terms of MOE of structural elements.

The application and determination of density using X-ray is well described by Lechner et al. (2013) [36]. The difficulties anticipated in the X-ray investigation for the verification process are the thickness of the hull structure, together with the high density of Vasa oak and the use of portable low-energy X-ray equipment in order not to disrupt the daily activities at the museum. Furthermore, the average density of the Vasa oak samples might be influenced by the lack of knowledge of the amount of PEG in the different pieces, which might 
influence the attenuation. The X-ray equipment is, however, assumed to be well suited to the estimation of the density, as the difference between the measured and the $\mathrm{X}$-rayed densities was shown to be small $(<4 \%)$.

\section{Summary and conclusions}

Based on the different aspects taken into account for the general structural assessment of the Vasa warship, the following conclusions can be drawn.

(1) The general complexity of the Vasa warship can be mainly attributed to large variations in Vasa oak; not only to the natural variability of the wood but also to the surface degradation, chemical treatment and the disintegration of the cell-wall structure originating from centuries of waterlogged conditions. This might cause difficulty in the assessment and evaluation of the mechanical and physical properties at structural level. A well-defined investigation procedure in three main steps therefore has to be applied in the evaluation of the mechanical properties, as described in this paper.

(2) X-ray investigations are of great importance in the evaluation of the mechanical and physical properties of the Vasa warship, as more accurate estimates can be obtained when assessing the condition of the structure when X-ray methods are used.

(3) The X-ray technique is a powerful tool for investigating the internal condition of the structure, especially when it comes to examining connections and the integrity between the structural components. The great advantage of X-rays over other methods is the non-destructive nature of this technique, which enables virtually an unlimited number of measurements without destruction of the material.

(4) The large variations in all the mechanical properties from the oak in the Vasa warship require more detailed investigations of these properties at the various locations in the ship's structure. This variation is mainly due to the content of PEG in and the origin of the test specimen (sapwood or heartwood), but it is probably also due to the natural morphological variation, which is especially pronounced in oak. The PEG treatment in combination with biological and chemical degradation before and after the salvage respectively has clearly influenced the mechanical properties negatively.

(5) The results from the detailed investigations and the determination of the material and mechanical properties using X-ray can serve as input in a future numerical computer model and might also serve as a foundation for decision-making relating to the adjustment and modification of the new support cradle.
(6) The on-site assessment and the analysis of the bearing capacity provide the basis for the choice of support of the hull in the best possible way. This implies a new and improved hydraulic adjustable support system including load cells at each supporting position to continuously monitor and control the system. A computer model can then verify and improve against both the reaction forces and the measured deformation and the support of the ship can be continuously adjusted and optimised according to the needs of the ship. An analysis of this kind could be very useful for decisions relating to strengthening and/or stiffening actions of the ship's structure.

\section{Abbreviations}

PEG: Polyethylene glycol; NDT: Non-destructive testing; RH: Relative humidity; T: Temperature; E: Modulus of elasticity; R: Radial; T: Tangential; L: Longitudinal; NMR: Nuclear magnetic resonance spectroscopy; MALDITOF: Matrix-assisted laser desorption/ionisation time-of-flight mass spectrometry; SEC: Size exclusion chromatography.

\section{Competing interests}

The authors declare that they have no competing interests.

\section{Authors' contributions}

$T L$ and IB are the main authors of this paper. TL performed the preliminary investigation of the non-destructive testing techniques and the X-ray investigation. IB contributed her extensive knowledge from her previous studies of Vasa oak. The co-operation between $\mathrm{TL}, \mathrm{IB}$ and RK led to the final suggestion for an investigation procedure combining the various research branches. All the authors have read and approved the final document.

\section{Acknowledgements}

(1) This research project has been financed by a research grant provided by the Swedish Research Council for Environment, Agricultural Sciences and Spatial Planning (FORMAS, No. 243-2008-1246).

(2) This article was produced in collaboration with the National Maritime Museums and, in particular, the Vasa Museum. We would also like to thank curators Emma Hocker and Malin Sahlstedt and chief engineer Anders Ahlgren at the museum for their kind help.

\section{Author details}

'Department of Civil and Environmental Engineering, Chalmers University of Technology, SE-412 96 Gothenburg, Sweden. ²Department of Engineering Sciences, Uppsala University (UU), Box 534, SE-751 21 Uppsala, Sweden.

Received: 13 August 2013 Accepted: 1 November 2013 Published: 26 November 2013

\section{References}

1. Bjurhager I: Effects of Cell Wall Structure on Tensile Properties of Hardwood. Doctoral thesis. Stockholm: Dept. of Polymer Technology, Royal Institute of Technology (KTH); 2011. ISBN 978-91-7415-914-1.

2. Capretti C, Macchioni N, Pizzo B, Galotta G, Giachi G, Giampaola D: The characterization of waterlogged archeaological wood: the three Roman ships found in Naples. Archaeometry 2008, 50(5):855-876.

3. Almkvist G, Persson I: Degradation of polyethylene glycol and hemicellulose in the Vasa. Holzforschung 2008, 62(1):64-70.

4. Håfors B: Book section: the role of the Wasa in the development of the polyethylene glycol preservation method, vol. 225. In Archaeological Wood. American Chemical Society; 1989:195-216.

5. Håfors B: Conservation of the Wood of the Swedish Warship Vasa of A.D. 1628 Evaluation of Polyethylene Glycol Conservation Programmes, Doctoral Thesis. Gothenburg: Gothenburg University; 2010. 
6. Schniewind AP: Physical and Mechanical Properties of Archaeological Wood, The Archaeological Wood: Properties, Chemistry and Preservation. Washington, DC: EE UU: American Chemical Society; 1990:87-109.

7. Ljungdahl J, Berglund LA, Burman M: Transverse anisotropy of compressive failure in European oak - a digital speckle photography study. Holzforschung 2006, 60(2):190-195.

8. Bjurhager I, Ljungdahl J, Wallström L, Gamstedt EK, Berglund LA: Towards improved understanding of PEG-impregnated waterlogged archaeological wood: a model study on recent oak. Holzforschung 2010, 64(2):243-250.

9. Ljungdahl J: Computer Based FE-model for Evaluation of the Support System to the Vasa Ship, Master's Thesis. Royal Institute of Technology: Stockholm; 2004

10. Sörenson M: Hull Strength of the Warship Vasa, Master's Thesis. Stockholm: Royal Institute of Technology; 1999.

11. Rosewarne S: Deformation study of the Vasa ship, Master's Thesis. Stockholm: Royal Institute of Technology; 2007.

12. Dinwoodie JM: Timber: Its nature and behaviour. 2nd edition. London: Taylor \& Francis; 2000.

13. Kollmann FFP, Cote WA Jr: Principles of Wood Science and Technology. I. Solid Wood. New York: Springer-Verlag; 1968.

14. Kasal B, Anthony RW: Advances in in-situ evaluation of timber structures. Prog Struct Eng Mater 2004, 6(2):94-103.

15. Mühlethaler B: Conservation of Waterlogged Wood and Wet Leather. Paris: Eyrolles; 1973

16. Ljungdahl J: Structure and Properties of Vasa Oak, Licentiate Thesis. Stockholm: Royal Institute of Technology, Dept. of Aeronautical and Vehicle Engineering, Stockholm; 2006.

17. Wallström L, Lindberg KAH: Wood surface stabilization with polyethyleneglycol, PEG. Wood Sci Technol 1995, 29(2):109-119.

18. Mohager S: Studier av krypning hos trä: med särskild hänsyn till inverkan av konstanta och cyklist varierande fukttillstånd. Stockholm: KTH - Institutionen för Byggnadsmateriallära; 1987.

19. Rug W, Seemann A: Strength of old timber: test cores from 50-400 year old timber indicates strength of old timbers corresponds to that of new. Build Res Inf 1991, 19(1):31-37.

20. Björdal CG, Nilsson T, Daniel G: Microbial decay of waterlogged archaeological wood found in Sweden applicable to archaeology and conservation. Int Biodeter Biodegr 1999, 43(1-2):63-73.

21. Hedges Jl: The Chemistry of Archaeological Wood, The Archaeological Wood: Properties, Chemistry, and Preservation. Washington, DC: EE UU: American Chemical Society; 1990.

22. FPL: Wood Handbook-Wood as an Engineering Material. Madison, Wisconsin: USDA Forest Service; 2010.

23. Bjurhager I, Gamstedt EK: Mechanical Testing and Properties of Vasa Oak - A Review, Creep behaviour of wood from the Vasa ship. Stockholm: Dept. of Fiber and Polymer Technology, Div. of Biocomposites, Royal Institute of Technology (KTH), Stockholm; 2011.

24. Thunell B: Undersökning av ekstycke från "Vasa". Träteknik: Svenska Träforskningsinstitutet; 1958.

25. Bjurhager I, Halonen H, Lindfors EL, Iversen T, Almkvist G, Gamstedt K, Berglund $L$ : State of degradation in archeological oak from the 17th century Vasa ship: substantial strength loss correlates with reduction in (Holo) cellulose molecular weight. Biomacromolecules 2012, 13(8):2521-2527.

26. Ljungdahl J: Mekanisk tryckprovning av PEG-impregnerad ek (in Swedish) Stockholm: Dept. of Aeronautical and Vehicle Engineering, Div. of Lightweight Structures, Royal Institute of Technology; 2007.

27. Ross RJ, Hunt MO: Stress Wave Timing Nondestructive Evaluation Tools for Inspecting Historic Structures: A Guide for Use and Interpretation. Madison WI, USA: General Technical Report Forest Products Laboratory, FPL-GTR-119, USDA Forest Service; 2000.

28. Bjurhager I, Nilsson H, Iversen T, Lindfors EL, Berglund LA: Mechanical properties of Vasa Oak in relation to cellulose degradation and chemical composition. In Stockholm. Stockholm: Dept. of Fiber and Polymer Technology, Royal Institute of Technology; 2008

29. Ljungdahl J, Berglund LA: Transverse mechanical behaviour and moisture absorption of waterlogged archaeological wood from the Vasa ship. Holzforschung 2007, 61(3):279-284.

30. Burman M, Ljungdahl J, Norrby M: Creep Tests of Wood from the Vasa Ship 2007-2009. Report. Stockholm: Dept. of Aeronautical and Vehicle Engineering, Div. of Lightweight Structures, Royal Institute of Technology (KTH); 2009.
31. Almkvist G: The Chemistry of Vasa - Iron, Acids and Degradation, Doctoral Thesis. Uppsala, Sweden: Swedish University of Agricultural Sciences; 2008.

32. Ljungdahl J: Mekanisk tryckprovning av ek från borrprover ur Vasa (in Swedish). Stockholm: Dept. of Aeronautical and Vehicle Engineering Div. of Lightweight Structures, Royal Institute of Technology; 2007.

33. Anthony R, Meade E: Assessment of a Mechanical Failure in a Historic Wood Truss Using Digital Radioscopy, From Material to Structure - Mechanical Behaviour and Failures of the Timber Structures. Venice and Vicenza: ICOMOS IWC - XVI International Symposium - Florence; 2007.

34. Feio AO: Inspection and Diagnosis of Historical Timber Structures: NDT Correlations and Structural Behaviour, Doctoral thesis. Minho, Portugal: University of Minho, Portugal; 2006.

35. Kasal B, Tannert T: In Situ Assessment of Structural Timber, RILEM State of the Art Reports Vol. 7. Springer; 2010.

36. Lechner T, Sandin Y, Kliger R: Assessment of density in timber using X-ray equipment. Int J Arch Herit 2013, 7(4):416-433.

37. Lindfors EL, Lindström $M$, Iversen $T$ : Polysaccharide degradation in waterlogged oak wood from the ancient warship Vasa. Holzforschung 2008, 62(1):57-63.

38. Schneider A: Beiträge zur dimensionsstabilisierung des holzes mit polyäthylenglykol zweite mitteilung: untersuchungen über eigenschaftsänderungen, des holzes durch tränkung mit polyäthylenglykol und über die wirksamkeit verschiedener tränkverfahren. Eur J Wood Wood Prod 1970, 28(1):20-34

39. Stamm AJ: Effect of polyethylene glycol on the dimensional stability of wood. For Prod J 1959, 9(10):375-381.

doi:10.1186/2050-7445-1-35

Cite this article as: Lechner et al: Strategy for developing a future support system for the Vasa warship and evaluating its mechanical properties. Heritage Science 2013 1:35.

Publish with ChemistryCentral and every
scientist can read your work free of charge
"Open access provides opportunities to our
colleagues in other parts of the globe, by allowing
anyone to view the content free of charge."
W. Jeffery Hurst, The Hershey Company.
- available free of charge to the entire scientific community
- peer reviewed and published immediately upon acceptance
- cited in PubMed and archived on PubMed Central
- yours - you keep the copyright
Submit your manuscript here:
http://www.chemistrycentral.com/manuscript/

